\title{
A Fusarium Wilt Resistance Gene in Gossypium barbadense and Its Effect on Root-Knot Nematode-Wilt Disease Complex
}

\author{
C. Wang and P. A. Roberts
}

Department of Nematology, University of California, Riverside 92521.

Accepted for publication 9 February 2006.

\begin{abstract}
Wang, C., and Roberts, P. A. 2006. A Fusarium wilt resistance gene in Gossypium barbadense and its effect on root-knot nematode-wilt disease complex. Phytopathology 96:727-734.

Fusarium wilt, caused by the soilborne pathogen Fusarium oxysporum f. sp. vasinfectum race 1, is a vascular disease in cotton (Gossypium spp.), and is a component of a disease complex with root-knot nematodes (Meloidogyne incognita). Genetic analysis of two interspecific crosses (G. barbadense Pima S-7 $\times$ G. hirsutum Acala NemX and Pima S-7 $\times$ Acala SJ-2) showed that one major gene (designated Fov1) with allele dosage effect conferred resistance to $F$. oxysporum f. sp. vasinfectum race 1 in Pima S-7. Two amplified fragment length polymorphism (AFLP) markers were linked to Fov1 in Pima S-7, with genetic distance from the gene of 9.3 and 14.6 centimorgans. Less severe wilt symptoms in Acala NemX than Acala SJ-2 indicated that Acala NemX possesses one or more

minor genes contributing to delay of wilt symptoms. Highly resistant plants in $\mathrm{F}_{2}$ and $\mathrm{F}_{3}(\mathrm{Pima} \mathrm{S}-7 \times \mathrm{NemX})$ families indicated transgressive segregation effects of minor genes in Acala NemX combined with Fov1 from Pima S-7. The effects of wilt and nematode resistance on the nematode-wilt disease complex were assayed with two inoculation methods. In the presence of both pathogens, wilt damage measured as shoot and root weight reductions was greatest on wilt- and nematode-susceptible Acala $\mathrm{SJ}-2$ and least in root-knot nematode-resistant and wilt-susceptible Acala NemX. Intermediate damage occurred in wilt-resistant and root-knot nematode-susceptible Pima S-7. The results indicated that nematode resistance was more effective than wilt resistance in suppressing wilt symptoms when either resistance was present alone. Nematode resistance combined with intermediate wilt resistance, as in the $\mathrm{F}_{1}$ (Pima S-7 $\times$ NemX), was highly effective in protecting plants from root-knot nematodes and race 1 of Fusarium wilt as a disease complex.
\end{abstract}

Fusarium wilt of cotton (Gossypium spp.) is a vascular disease caused by the soilborne pathogen Fusarium oxysporum f. sp. vasinfectum. It is widespread and causes substantial crop losses in most of the major cotton-producing areas of the world. The incidence, rate of development, and severity of Fusarium wilt in cotton can increase in the presence of root-knot nematodes (Meloidogyne incognita) as a disease complex $(1,10)$. Garber (11) found that Fusarium wilt symptoms occurred with $\geq 77,000 F$. oxysporum $\mathrm{f}$. sp. vasinfectum propagules per gram of soil without root-knot nematode on root-knot nematode-susceptible Acala SJ-2, whereas as few as $650 \mathrm{~F}$. oxysporum f. sp. vasinfectum propagules caused Fusarium wilt on plants co-inoculated with 50 root-knot nematode infective juveniles under controlled greenhouse conditions. Fusarium wilt disease symptoms of cotton appeared sooner with an increase of population levels of either or both $M$. incognita and F. oxysporum f. sp. vasinfectum (11). In California, Fusarium wilt symptoms typically are associated with the presence of $M$. incognita in fields with coarse-textured sandy soils $(10,17)$. In the San Joaquin Valley of California, root-knot nematode-Fusarium wilt complex infection occurs in up to $20 \%$ of the cotton-planting area $(2,12)$. During the last 50 years, the nematode and wilt disease complex has been controlled effectively with fumigant nematicides (19). More restrictive uses of nematicides, due to environmental and human health concerns and economic considerations, have resulted in greater emphasis on the development of resistant cultivars for the management of nematodes and wilt disease. Resistance to $M$. incognita has proved to be an effective control strategy for the root-knot nematode-Fusarium wilt disease complex $(24,27)$.

Corresponding author: P. A. Roberts; E-mail address: philip.roberts@ucr.edu

DOI: 10.1094/PHYTO-96-0727

(c) 2006 The American Phytopathological Society
In California, four races (races $1,3,4$, and 8) of $F$. oxysporum $\mathrm{f}$. sp. vasinfectum were reported by Kim et al. (20). Races 1, 3, and 8 are mildly virulent and cause little or no wilt symptoms in the absence of root-knot nematodes. Race 1 , the focus of this study, is widely distributed in the San Joaquin Valley and has been the predominant form of $F$. oxysporum f. sp. vasinfectum. Race 3 and race 8 were identified recently in a limited number of fields in Tulare and Fresno counties (20). However, race 4 of $F$. oxysporum f. sp. vasinfectum, which also was identified recently in California (20), caused severe wilt symptoms and economic loss in Pima (G. barbadense L.) cotton fields in the San Joaquin Valley, even in the absence of nematodes. The occurrence and threat of new races or virulent strains of $F$. oxysporum $\mathrm{f}$. sp. vasinfectum emphasizes the need to develop cultivars with multiple resistance to different races or strains and multiple pathogens. For example, California imports tons of seed for cattle feed from Australia (20), which has extremely virulent strains of $F$. oxysporum f. sp. vasinfectum that cause extensive damage to Australian cotton in the absence of root-knot nematodes (9). An improved understanding of genetic resistance to each race or strain is an important step towards incorporating resistance genes into elite cultivars. Previous reports about the genetic resistance to Fusarium wilt mostly focused on nematode-wilt disease complex in field experiments, revealing one to several genes involved in Fusarium wilt resistance $(13,15,18,28,29)$. Netzer et al. (23) reported one dominant gene involved in determining resistance to race 3 of $F$. oxysporum f. sp. vasinfectum in Acala SJ-2 in Israel under greenhouse conditions.

In contrast to phenotypic selection, which is time-consuming, expensive, and sensitive to screening conditions, marker-assisted selection, based on identification of DNA markers linked to Fusarium wilt resistance genes in cotton, will allow wide selection of wilt resistance in cotton breeding. Genetic markers also will enable unique resistance genes to be pyramided in one genotype or to be deployed individually. 
The objectives of this study were to (i) determine the inheritance of resistance to $F$. oxysporum $\mathrm{f}$. sp. vasinfectum race 1 in G. barbadense cv. Pima S-7, (ii) screen for amplified fragment length polymorphism (AFLP) markers linked to Fusarium wilt resistance, and (iii) determine the effects of the wilt resistance on the interaction between $M$. incognita and $F$. oxysporum f. sp. vasinfectum race 1 .

\section{MATERIALS AND METHODS}

Plant materials and crosses. Plant genotypes used in this study were $G$. hirsutum cv. Acala SJ-2, G. hirsutum cv. Acala NemX, and G. barbadense cv. Pima S-7. One intraspecific cross was made between Acala NemX and Acala SJ-2, and two interspecific crosses were made between Pima S-7 and Acala NemX, and between Pima S-7 and Acala SJ-2. The $F_{1}$ plants were selfed to produce $\mathrm{F}_{2}$ and also backcrossed to both parents to produce $\mathrm{BC}_{1} \mathrm{~F}_{1}$ populations. Sixty-eight $\mathrm{F}_{2}($ Pima $\mathrm{S}-7 \times \mathrm{NemX})$ plants were selfed to obtain $\mathrm{F}_{2: 3}$ families for Fusarium wilt screening. All plants for crossing and producing seed were planted in 15-cm-diameter pots filled with steam-sterilized U.C. Mix \#2 (3) soil and grown in the greenhouse. Air temperatures in the greenhouse were maintained between 28 and $35^{\circ} \mathrm{C}$ during the day and $24^{\circ} \mathrm{C}$ at night. Plants were fertilized with 17-6-10 controlled release fertilizer (Scotts-Sierra Horticultural Products Co.) and were drip irrigated.

Fungus inoculum. Four isolates of $F$. oxysporum f. sp. vasinfectum from two Fresno County fields $(2 \mathrm{~F}$ and $3 \mathrm{~F})$ in California were kindly provided by Dr. Shirley N. Smith, Plant Pathology Department, University of California, Davis (Table 1). Isolates I and III belong to the high-sporulating culture type $\left(\mathrm{FOV}_{\mathrm{HS}}\right)$, which produces conidia rapidly, a red-purple pigment in potato dextrose agar (PDA) and other culture media, and an unusual, fragrant odor. Isolates II and IV are low-sporulating culture types $\left(\mathrm{FOV} \mathrm{LS}_{\mathrm{LS}}\right)$, with slow conidia production, no pigmentation, and no fragrance $(30,31)$. Isolates I, III, and IV were identified as race 1 and isolate II as race 8 by Kim et al. (20). Cultures from single spores were stored on filter paper at $-20^{\circ} \mathrm{C}$. To produce inoculum, the isolates were grown in 9-cm-diameter petri dishes containing $20 \mathrm{ml}$ of PDA with $3 \mathrm{mM}$ streptomycin per liter at room temperature for 1 week. The spore suspensions were prepared by adding distilled water onto the culture grown in petri dishes, scraping the agar surface with a glass slide, and filtering the suspension through four layers of cheesecloth. Fusarium spore suspensions were adjusted to desired concentrations for each experiment using a hemacytometer.

Nematode inoculum. A culture of $M$. incognita race 3 (isolate Project 77), originating from a San Joaquin Valley, California cotton field, was maintained and multiplied on tomato cv. Tropic. The species and race identity of the culture were confirmed by

TABLE 1. Pathogenicity of four Fusarium oxysporum f. sp. vasinfectum isolates from the San Joaquin Valley, California, on three cotton cultivars (Pima S-7, Acala NemX, and Acala SJ-2) ${ }^{\mathrm{z}}$

\begin{tabular}{lcccc}
\hline & & \multicolumn{3}{c}{ Disease index } \\
\cline { 3 - 5 } Isolates & Race & $\mathrm{SJ}-2$ & NemX & Pima S-7 \\
\hline I & 1 & $5.00 \mathrm{a}$ & $4.08 \mathrm{a}$ & $1.33 \mathrm{a}$ \\
II & 8 & $4.53 \mathrm{~b}$ & $4.29 \mathrm{a}$ & $0.87 \mathrm{a}$ \\
III & 1 & $4.93 \mathrm{a}$ & $4.11 \mathrm{a}$ & $1.67 \mathrm{a}$ \\
IV & 1 & $4.87 \mathrm{ab}$ & $4.23 \mathrm{a}$ & $1.75 \mathrm{a}$ \\
$P>F$ & $\ldots$ & 0.0418 & 0.9441 & 0.4098 \\
LSD & $\ldots$ & 0.3424 & 0.7877 & 1.0697 \\
\hline
\end{tabular}

${ }^{\mathrm{z}}$ Data are the means of 20 replicate plants per treatment. Observations were made 3 weeks after inoculation using the root-cut dip method. $P=$ probability level of analysis of variance; LSD = least significance difference at the 0.05 level. Means within a column with the same letter are not different. Disease index, 0 -to-5 scale, where $0=$ no symptoms and $5=$ plant death . Noninoculated control plants remained healthy (data not shown). isozyme phenotyping and a host differential test as described previously (26). Inoculum was prepared by extracting eggs from tomato roots with $\mathrm{NaOCl}(14)$.

Fusarium wilt assays. A root-cut dip method described by Smith et al. (31) with modifications was performed for the F. oxysporum f. sp. vasinfectum pathogenicity tests. One-weekold seedlings grown in seedling trays were uprooted, and roots were rinsed with tap water, trimmed to 2 to $3 \mathrm{~cm}$ in length, and immediately dipped for $3 \mathrm{~min}$ into an aqueous suspension of Fusarium macro- and microconidia $\left(1 \times 10^{6}\right.$ conidia/ml $)$. Seedlings then were transplanted into steam-sterilized U.C. Mix \#2 (3) soil in new pots with five plants in each pot. Disease severity was measured weekly for 3 weeks after inoculation. To study disease progress in three parents (Pima S-7, Acala SJ-2, and Acala NemX $)$ and two $F_{1}$ cotton genotypes $\left(F_{1}\left[\right.\right.$ Pima S-7 $\times$ SJ-2] and $F_{1}$ [Pima S-7 $\times$ NemX]), symptoms were indexed starting at 7 days and continuing every 1 to 2 days until 4 weeks after inoculation. This experiment was conducted twice. Individual plants were rated for disease severity based on the following index: $0=$ no symptoms, $1=$ epinasty and slight dwarfing, $2=1$ to $30 \%$ chlorotic leaves, $3=31$ to $80 \%$ chlorotic leaves and severe stunting, $4=81$ to $100 \%$ chlorotic leaves, and $5=$ plant death. The stems were cut longitudinally and evaluated for vascular discoloration. Two to four $1-\mathrm{cm}$ segments were cut and plated on PDA agar for reisolation of $F$. oxysporum $\mathrm{f}$. sp. vasinfectum.

Plants with a disease index $\leq 2$ were classified as resistant and those with an index $>2$ as susceptible, based on comparisons with the indices of the resistant Pima S-7 and susceptible Acala SJ-2 and Acala NemX parents (Fig. 1). In the segregating $F_{2}($ Pima $S-7 \times$ $\mathrm{NemX})$ population, plants were identified as homozygous resistant when all individual plants in the $\mathrm{F}_{2: 3}$ family were resistant, as homozygous susceptible when all individual $\mathrm{F}_{2: 3}$ plants were susceptible, and as heterozygous when plants in an $\mathrm{F}_{2: 3}$ family segregated susceptible and resistant. Each experiment for genetic analysis of $F$. oxysporum $\mathrm{f}$. sp. vasinfectum included the parents and $\mathrm{F}_{1}$.

Disease interaction assays. To evaluate the effects of wilt and nematode resistance on the interaction of $F$. oxysporum $\mathrm{f}$. sp.

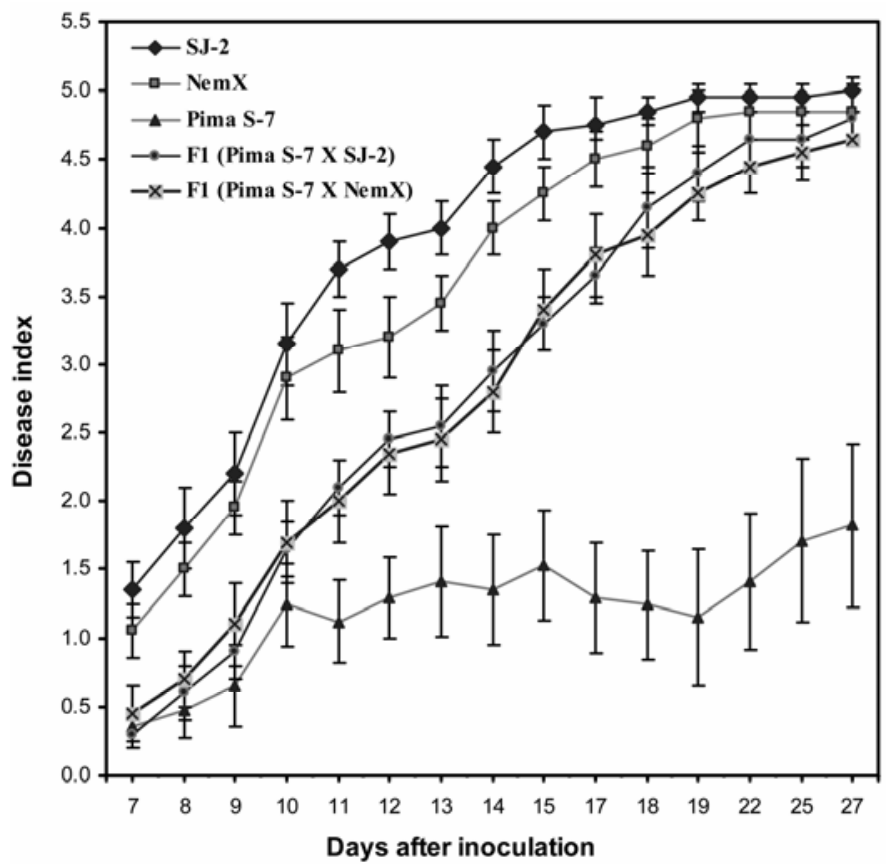

Fig. 1. Progress of wilt disease symptoms of Fusarium oxysporum f. sp. vasinfectum race 1 on three cotton cultivars and two $F_{1}$ after inoculation with the root-cut dip inoculation method. Data are the means of 20 replicate plants per treatment. Bars show \pm one standard error. Disease index: 0 -to- 5 scale $(0=$ no symptom and $5=$ plant death). 
vasinfectum and $M$. incognita, two inoculation methods and four treatments were used (plants with $M$. incognita alone, with $F$. oxysporum f. sp. vasinfectum alone, with $M$. incognita and F. oxysporum f. sp. vasinfectum, and with neither pathogen). In the first method (seedling method), 10-day-old seedlings grown in 10 -cm-diameter pots filled with $0.45 \mathrm{~kg}$ of steam-sterilized sandy soil (93\% sand, 3\% clay, and 4\% silt) were inoculated with $20,000 \mathrm{M}$. incognita eggs in $5 \mathrm{ml}$ of water and with $30 \times 10^{6}$ F. oxysporum f. sp. vasinfectum spores in $5 \mathrm{ml}$ of water via two holes made around each plant. The control plants were inoculated with only distilled water at equivalent volumes. In the second inoculation method (soil method), which was used to simulate field conditions, $F$. oxysporum f. sp. vasinfectum spores were mixed into soil before planting. This method was modified from that described by Garber et al. (11). Each 10-cm-diameter pot contained $0.45 \mathrm{~kg}$ of sandy soil with or without $30 \times 10^{6} \mathrm{~F}$. oxysporum f. sp. vasinfectum spores. The inoculum was mixed into soil before soil was placed in pots and planted with one seed per pot. In treatments including nematodes, the soil was infested by pouring a 5-ml suspension containing 20,000 M. incognita eggs over the seed before it was covered. The control plants were inoculated with only distilled water. Treatments were arranged in a randomized complete block design with nine replications. The two inoculation methods were used in separate experiments, and each of the experiments was conducted twice (trials 1 and 2). Data on plant height, fresh shoot weight, fresh root weight, and nematode eggs per gram of root were collected 60 days after inoculation. The height of each plant was measured from the soil surface to the growing tip. The stems were cut longitudinally and evaluated for vascular discoloration. Two to four 1-cm segments were cut and plated on PDA agar for re-isolation of $F$. oxysporum f. sp. vasinfectum.

To provide optimal conditions for plant growth and for infection by both pathogens, heat mats under pots maintained soil temperature at $28^{\circ} \mathrm{C}$ in all experiments. Air temperatures in the greenhouse were maintained between 28 and $32^{\circ} \mathrm{C}$ during the day and $24^{\circ} \mathrm{C}$ at night. Plants were fertilized with 17-6-10 controlled release fertilizer (Scotts-Sierra Horticultural Products Co.) and pots were drip irrigated.

Data were analyzed using analysis of variance procedure of the SAS statistical software (SAS Institute, Cary, NC). Nematode egg data were $\log _{10}(x+1)$ transformed before analysis.

DNA extraction and AFLP screening. Fresh or frozen $\left(-80^{\circ} \mathrm{C}\right)$ young cotton leaves were ground to a fine powder in liquid nitrogen using a mortar and pestle, and genomic DNA was extracted using the DNeasy Plant Mini kit (Qiagen, Valencia, CA).

Screening of AFLP markers linked to Fusarium wilt resistance was based on the bulked segregant analysis (BSA) method (22). Two DNA pools were made, one with seven homozygous resistant plants and the second with seven homozygous susceptible plants from the $\mathrm{F}_{2}($ Pima S-7 $\times$ NemX) population based on phenotype screening of $\mathrm{F}_{2: 3}($ Pima S-7 $\times$ NemX) families. The bulks together with the two parents were screened for markers showing polymorphisms between the four samples. The AFLP markers with putative linkage to the $F$. oxysporum $\mathrm{f}$. sp. vasinfectum resistance gene (Fovl) in Pima S-7 were confirmed by screening the individuals within the bulks. The confirmed markers were analyzed further and mapped using an additional $36 \mathrm{~F}_{2}$ individual plants segregating for Fovl based on $\mathrm{F}_{2: 3}$ family tests. AFLPs were generated using the protocol of IRDye Fluorescent AFLP Kit for large plant genome analysis (LI-COR, Lincoln, NE) with modifications. The half volumes of the protocol described were used for restriction and ligation of genomic DNA and preamplification of the diluted template DNA. In all, 80 primer combinations (EcoRI/MseI), including 8 IRDye-labeled EcoRI primers plus three nucleotides (AAC, AAG, ACA, ACT, ACC, ACG, AGC, and AGG) and 10 unlabeled MseI primer plus three nucleotides (CAA, CAC, CAG, CAT, CTA, CTC, CTG, CTT, CGA, and CCG) (LI-COR) were used for selective amplification. Amplification was performed in a MasterCycler Gradient (Eppendorf, Hamburg, Germany). Electrophoresis and detection were performed on a two-dye, model 4000 LI-COR IR ${ }^{2}$ automated sequencer (Global edition, LI-COR). The gel images were analyzed with Saga automated analysis software (LI-COR).

Segregation and linkage analysis. The data for $F$. oxysporum f. sp. vasinfectum resistance phenotype and marker segregation ratios were tested for goodness-of-fit to predicted Mendelian inheritance ratios by the $\chi^{2}$ test $(P=0.05)$. The linkage analysis between the AFLP markers and $F$. oxysporum $\mathrm{f}$. sp. vasinfectum resistance locus was performed with the software JoinMap 3.0. The linkage groups were intact up to a log of the likelihood ratio score of 6 . The recombination fractions were converted into centimorgans (cM) based on Kosambi's mapping function (21).

\section{RESULTS}

Pathogenicity of four $F$. oxysporum f. sp. vasinfectum isolates. This experiment was conducted twice (trial 1 and trial 2). Analysis of variance showed no difference between the duplicate trials 1 and 2, and only data from trial 2 are presented (Table 1). All control plants not inoculated with the Fusarium sp. remained healthy (data not shown). There was no difference in pathogenicity among the four isolates within one cotton genotype except that isolate II was less virulent than the other three isolates on Acala SJ-2 (Table 1). At the end of the experiment, almost all inoculated plants of Acala SJ-2 and Acala NemX had died, whereas Pima S-7 plants were growing well even though the plants had mild wilt symptoms with stunting. Wilt disease symptoms in Acala SJ-2 and Acala NemX included cotyledon drop, leaf chlorosis and necrosis, plant wilt, and plant death starting at 10 days after inoculation. The growth of Acala SJ-2 and Acala NemX plant stems was limited to the first node, and plants remained stunted until death. Pima S-7 plants grew slowly for a few days after transplanting and then recovered and grew to the second stem node and above. Vascular discoloration occurred along the length of the stem in all plants of Acala NemX and Acala SJ-2, whereas vascular discoloration was limited to the lower part of the stem just above the soil level in Pima S-7. These data showed that Acala SJ-2 and Acala NemX were susceptible and Pima S-7 was resistant but not immune to $F$. oxysporum $\mathrm{f}$. sp. vasinfectum. To analyze the inheritance of resistance to $F$. oxysporum f. sp. vasinfectum in Pima S-7 and to determine the effects of the wilt resistance on the nematode-wilt disease complex, isolate I was used for the following experiments.

Disease progress of $F$. oxysporum f. sp. vasinfectum in parents and $\mathbf{F}_{1}$. Wilt disease symptoms caused by $F$. oxysporum f. sp. vasinfectum race 1 on the three cotton parents (Pima S-7, Acala NemX, and Acala SJ-2) and two $F_{1}($ Pima S-7 $\times$ NemX and Pima S-7 $\times$ SJ-2) increased with time after inoculation in all genotypes (Fig. 1). The symptoms started to appear 6 days after inoculation in Acala SJ-2, Acala NemX, and the two $F_{1}$. Some plants started to die 10 days after inoculation in Acala NemX and Acala SJ-2 and 14 days after inoculation in the two $F_{1}$. Acala NemX had fewer wilt symptoms than Acala SJ-2. The progress of wilt disease in the two $F_{1}$ was intermediate between Pima S-7 and Acala NemX or Acala SJ-2 11 to 17 days after inoculation (Fig. 1). The severity of disease in the two $F_{1}$ was less than on both susceptible parents from the onset of symptoms (day 6 to 7) until day 18 , from which time on the $F_{1}$ showed severe symptoms similar to the susceptible parents. Conversely, the severity of disease in Pima S-7 was less than in Acala SJ-2 and Acala NemX on all assay dates, and less than in the $F_{1}$ after day 10 (Fig. 1). The mean disease index in Pima S-7 remained low during the experiment (Fig. 1). Based on these results, plants were harvested 21 days after inoculation in the genetic analysis experiments. 
Phenotypic and genetic analysis of $F$. oxysporum f. sp. vasinfectum resistance in segregating populations. Inheritance of resistance to $F$. oxysporum $\mathrm{f}$. sp. vasinfectum race 1 was studied in segregating populations derived from two crosses between resistant Pima S-7 and either susceptible Acala NemX or Acala SJ-2. The observed resistant:susceptible (R:S) ratios in different generations or segregating populations fit R:S ratios expected for a model of one gene determining resistance in Pima S-7 (Table 2). Among the susceptible parents, less severe wilt symptoms were observed consistently in Acala NemX compared with Acala SJ-2 in all tests using the root-cut dip method (Tables 1 and 2; Fig. 1), indicating that Acala NemX carried minor resistance genes contributing to delay in the development of wilt symptoms. The progress of disease over 3 weeks in susceptible plants showed a trend of accumulating wilt severity (Fig. 1). All Acala SJ-2 and $F_{1}$ (Pima S-7 $\times \mathrm{SJ}-2$ ) plants were highly susceptible to $F$. oxysporum f. sp. vasinfectum, but some plants of Acala NemX and the $F_{1}$ (Pima S-7 $\times$ NemX) were less susceptible. In addition, when both $\mathrm{F}_{1}\left(\right.$ Pima S-7 $\times$ NemX) and $\mathrm{F}_{1}(\mathrm{NemX} \times$ Pima S-7) were backcrossed to Pima $S-7$, the observed R:S ratios were $>1: 1$, whereas the observed R:S ratios were $<1: 1$ in the backcross populations of Pima S-7 $\times \mathrm{F}_{1}\left(\right.$ Pima S-7 $\times$ SJ-2) and Pima S-7 $\times \mathrm{F}_{1}(\mathrm{SJ}-2 \times$ Pima $\mathrm{S}-7$ ) (Table 2). These results indicated a small but consistent difference in wilt susceptibility between Acala SJ-2 and Acala NemX. In all, 12 of $57 \mathrm{BC}_{1}$ Acala $\mathrm{NemX} \times \mathrm{F}_{1}($ Pima S-7 $\times$ NemX) plants and 2 of $61 \mathrm{BC}_{1}$ Acala SJ- $2 \times \mathrm{F}_{1}($ Pima S-7 $\times \mathrm{SJ}-2)$ plants were scored as resistant among all expected susceptible plants (Table 2), further indicating lower susceptibility in Acala NemX. Higher resistance than in the resistant parent Pima S-7 also was observed in some $\mathrm{F}_{2}$ and $\mathrm{F}_{3}($ Pima $\mathrm{S}-7 \times \mathrm{NemX})$ families. In addition, five individuals had susceptible responses in resistant Pima S-7 and some plants showed resistant responses among expected susceptible plants (Table 2).

AFLP markers associated with resistance to $F$. oxysporum $f$. sp. vasinfectum race 1. Of $80 \mathrm{AFLP}$ EcoRI/MseI primer combinations, 13 were tested for potential association with Fusarium resistance based on BSA. After individuals within the bulks were screened, 10 potential markers within eight primer combinations were used to screen the $\mathrm{F}_{2}($ Pima S-7 $\times$ NemX) individual plants. Based on the wilt resistance assays of $\mathrm{F}_{2: 3}$ families to determine the $F_{2}$ phenotype, two coupling-phase dominant markers (M-
CAA_E-AAC-85 and M-CAA_E-AGC-169; Fig. 2A and B, respectively) were found to be linked to the major gene determining resistance in Pima S-7, with distances from the resistance gene of 9.3 and $14.6 \mathrm{cM}$, respectively (Fig. 2C).

Effect of resistance on the nematode-wilt disease complex. Experiments on the effects of single and combined inoculations with $M$. incognita and $F$. oxysporum $\mathrm{f}$. sp. vasinfectum race 1 on the three cotton cultivars with both the seedling and the soil method were conducted twice (trials 1 and 2). Similar results were obtained between trials based on analysis of variance, and the results presented are from one trial for each inoculation method. No wilt symptoms were observed in the noninoculated control or the nematode-only treatment (data not shown). Among plants inoculated with $F$. oxysporum f. sp. vasinfectum race 1 alone, only Acala SJ-2 plants inoculated by the soil method showed wilt symptoms (data not shown). Plants inoculated with both pathogens were shorter and weighed less than noninoculated plants and plants inoculated with either $M$. incognita or $F$. oxysporum f. sp. vasinfectum alone (Tables 3 and 4). The percent reduction in plant height, shoot weight, and root weight in the presence of both pathogens was greater in all three cultivars compared with the control, M. incognita, and $F$. oxysporum f. sp. vasinfectum treatments. The greatest reduction in plant growth was in Acala SJ-2, followed by Pima S-7 and then Acala NemX. Growth of Acala SJ-2 inoculated with $M$. incognita was less than growth of noninoculated plants regardless of inoculation method (Tables 3 and 4). Shoot weight of Pima S-7 inoculated with M. incognita by the soil method was less than that of the control (Table 4).

In Acala SJ-2 inoculated by the soil method (Table 4) but not by the seedling method (Table 3), plant height, shoot weight, and root weight were less in the $F$. oxysporum $\mathrm{f}$. sp. vasinfectum alone treatment than in the $M$. incognita and control treatments.

In the $M$. incognita treatment, numbers of nematode eggs were equivalent in the nematode-susceptible genotypes Pima S-7 and Acala SJ-2, and greater in the susceptible genotypes than in the resistant Acala NemX. Nematode egg production in Acala SJ-2 plants infected with both $M$. incognita and $F$. oxysporum f. sp. vasinfectum pathogens was lower than in the $M$. incognita alone treatment (Table 5).

Vascular discoloration was observed in stem tissues of all three cultivars in the presence of both pathogens. Acala SJ-2 plants

TABLE 2. Classification for resistance to Fusarium oxysporum f. sp. vasinfectum race 1 of parent lines and segregating populations derived from crosses of resistant Pima S-7 with susceptible Acala NemX and susceptible Acala SJ-2, using root-cut dip inoculation method ${ }^{\mathrm{v}}$

\begin{tabular}{|c|c|c|c|c|c|}
\hline Genotype, population & No. of plants & Expected ratio $^{\mathrm{w}}$ & Observed ratio R:S & $\chi^{2}$ & $P$ value \\
\hline \multicolumn{6}{|c|}{ Pima S-7 $(\mathrm{P}) \times \operatorname{NemX}(N)^{\mathrm{x}}$} \\
\hline Pima S-7 & $43^{y}$ & All R & $38: 5$ & $\ldots$ & $\ldots$ \\
\hline NemX & $44^{y}$ & All S & $5: 39$ & $\ldots$ & $\ldots$ \\
\hline $\mathrm{F}_{2}(\mathrm{P} \times \mathrm{N})$ & 133 & 33.25:99.75 (1:3) R:S & $31: 102$ & 0.2030 & 0.6523 \\
\hline $\mathrm{F}_{3}$ families $^{\mathrm{z}}$ & $68^{\mathrm{z}}$ & 17:34:17 (1:2:1) R:Seg:S & $15: 34: 19$ & 0.4706 & 0.7903 \\
\hline \multicolumn{6}{|l|}{$\mathrm{BC}_{1} \mathrm{~F}_{1}$} \\
\hline $\mathrm{P} \times \mathrm{F}_{1}(\mathrm{P} \times \mathrm{N})$ & 85 & $42.5: 42.5(1: 1) \mathrm{R}: \mathrm{S}$ & $51: 34$ & 3.4000 & 0.0652 \\
\hline \multicolumn{6}{|l|}{ Pima S-7 $(\mathrm{P}) \times \mathrm{SJ}-2(\mathrm{~S})$} \\
\hline Pima S-7 & $43^{y}$ & All R & $38: 5$ & $\ldots$ & $\ldots$ \\
\hline SJ-2 & $50^{y}$ & All S & $0: 50$ & $\ldots$ & $\ldots$ \\
\hline $\mathrm{F}_{1}(\mathrm{P} \times \mathrm{S})$ & $67^{y}$ & All S & $0: 67$ & $\ldots$ & $\ldots$ \\
\hline $\mathrm{F}_{2}(\mathrm{P} \times \mathrm{S})$ & 143 & 35.75:107.25 (1:3) R:S & $30: 113$ & 1.2331 & 0.2668 \\
\hline \multicolumn{6}{|l|}{$\mathrm{BC}_{1} \mathrm{~F}_{1}$} \\
\hline $\mathrm{P} \times \mathrm{F}_{1}(\mathrm{P} \times \mathrm{S})$ & 89 & 44.5:44.5 (1:1) R:S & $40: 49$ & 0.9101 & 0.3401 \\
\hline
\end{tabular}

\footnotetext{
${ }^{v}$ These data were collected from two tests. The first test included three parents (Pima S-7, NemX, and SJ-2) and corresponding $F_{1}, F_{2}$, and $34 F_{3}(P \times N)$ families.

The second test included three parents and two $\mathrm{F}_{1}$, plus all corresponding $\mathrm{BC}_{1} \mathrm{~F}_{1}$ populations and another $34 \mathrm{~F}_{3}(\mathrm{P} \times \mathrm{N})$ families.

${ }^{\text {w }}$ Expected number of plants for a single gene model of resistance. $\mathrm{R}=$ resistant, $\mathrm{S}=$ susceptible, and Seg = segregating.

${ }^{x} \mathrm{P}=$ Pima S-7; $\mathrm{N}=\mathrm{NemX} ; \mathrm{S}=\mathrm{SJ}-2 ; \mathrm{F}_{1}(\mathrm{P} \times \mathrm{N})=\mathrm{F}_{1}(\mathrm{Pima} \mathrm{S}-7 \times \mathrm{NemX})$, and so on.

${ }^{\mathrm{y}}$ The number of plants or families tested are pooled from two tests.

${ }^{\mathrm{z}}$ Each family included 15 to 25 individual plants.
} 

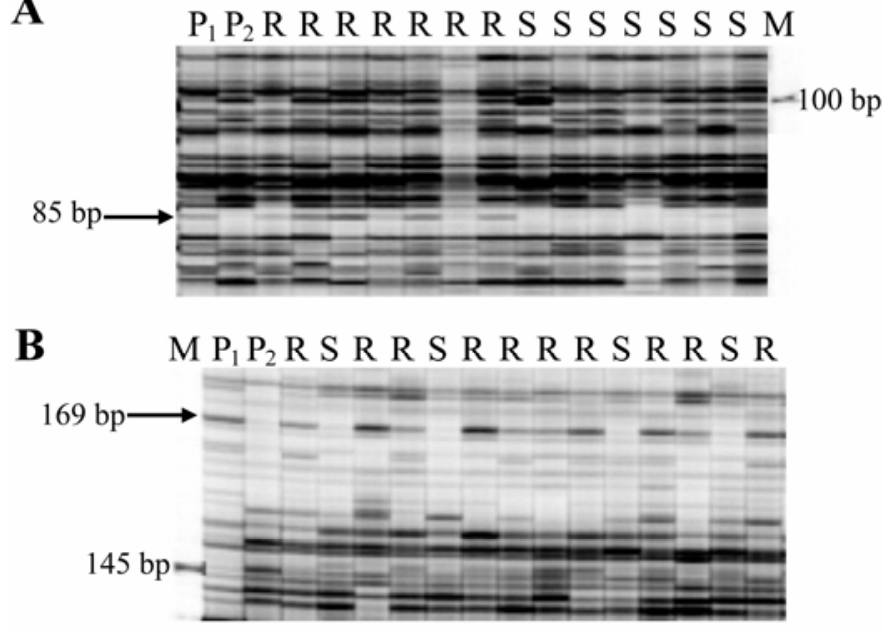

C

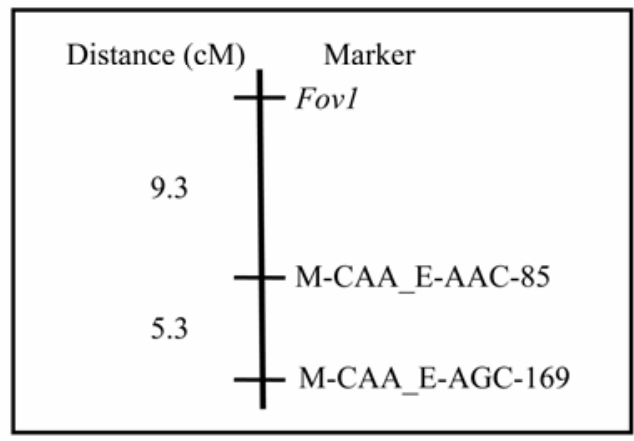

Fig. 2. Images of amplification products with dominant amplified fragment length polymorphism (AFLP) markers A, M-CAA_E-AAC-85 and B, MCAA_E-AGC-169 in the segregating population $\mathrm{F}_{2}($ Pima S-7 $\times$ NemX) electrophoresed on polyacrylamide gel with model 4000 LI-COR IR ${ }^{2}$ automated sequencer and $\mathbf{C}$, location of Fusarium oxysporum f. sp. vasinfectum race 1 resistance gene Fov1 in Pima S-7 relative to the two AFLP markers in the $\mathrm{F}_{2}$ (Pima S-7 $\times$ NemX) population. Linkage shown at log of the likelihood ratio $=6 . \mathrm{P}_{1}=$ Pima $\mathrm{S}-7, \mathrm{P}_{2}=\mathrm{NemX}, \mathrm{R}=$ resistant, and $\mathrm{S}=$ susceptible, all based on phenotype; $\mathrm{M}=700$-bp ladder. The arrows point to the marker positions. M-CAA_E-AAC-85 indicates that MseI (CAA) and EcoRI (AAC) primer combination produced an 85-bp-size marker. with both pathogens started to die 25 days after inoculation in experiments with both inoculation methods, and all Acala SJ-2 plants had died by the end of the experiments. Vascular discoloration was limited to the lower part of the stem in Acala NemX. Dark vascular discoloration was limited to the first stem node in Pima S-7, with no discoloration between the first and second nodes.

The three $F_{1}$ genotypes also were included in the interaction experiments above. In $\mathrm{F}_{1}(\mathrm{Pima} \mathrm{S}-7 \times \mathrm{SJ}-2)$ and $\mathrm{F}_{1}(\mathrm{SJ}-2 \times$ NemX), shoot weight was less in plants inoculated with both $M$. incognita and $F$. oxysporum $\mathrm{f}$. sp. vasinfectum than in noninoculated plants or in plants inoculated with $M$. incognita or F. oxysporum f. sp. vasinfectum alone by both the soil method (Fig. 3) and the seedling method (data not shown); similar results were obtained with plant height and root weight (data not shown). However, in $\mathrm{F}_{1}($ Pima S-7 $\times \mathrm{NemX}$ ), shoot weights (and plant height and root weight; data not shown) were similar in all four treatments (Fig. 3). As with susceptible plants inoculated by the seedling method, numbers of nematodes in the $M$. incognita alone treatments were similar in the susceptible genotypes and were greater in the susceptible $\mathrm{F}_{1}(\mathrm{Pima} \mathrm{S}-7 \times \mathrm{SJ}-2)$ and $\mathrm{F}_{1}(\mathrm{SJ}-2 \times$ NemX) genotypes than in the resistant $F_{1}($ Pima S-7 $\times$ NemX) genotype (data not shown).

\section{DISCUSSION}

Genetic analysis of the two crosses Pima S-7 $\times$ SJ-2 and Pima S-7 $\times$ NemX indicated that one major gene with allele dosage effect in Pima S-7 conferred resistance to race 1 of $F$. oxysporum f. sp. vasinfectum. This gene is designated here as Fovl. In addition, less severe wilt symptoms in wilt-susceptible Acala NemX than in Acala SJ-2 indicated that one or more minor genes in Acala NemX contributed to the delay in the development of wilt symptoms and to the small but significant reduction in the severity of wilt symptoms. The presence of some plants in $\mathrm{F}_{2}$ and $\mathrm{F}_{3}$ (Pima S-7 $\times$ NemX) families with higher resistance than in resistant parent Pima S-7 suggested that transgressive inheritance occurred and that minor genes in Acala NemX contributed to the resistance in combination with Fov1. Transgressive inheritance of resistance to $M$. incognita also was observed in $\mathrm{F}_{2: 7}(\mathrm{NemX} \times \mathrm{SJ}$ 2) and $F_{2}, F_{3}$ and backcross populations of Pima S-7 $\times$ NemX

TABLE 3. Effects of single and combined inoculations (using the seedling method) with Meloidogyne incognita (RKN) and Fusarium oxysporum f. sp. vasinfectum (FOV) race 1 on plant growth of three cotton cultivars (Acala SJ-2, Acala NemX, and Pima S-7)

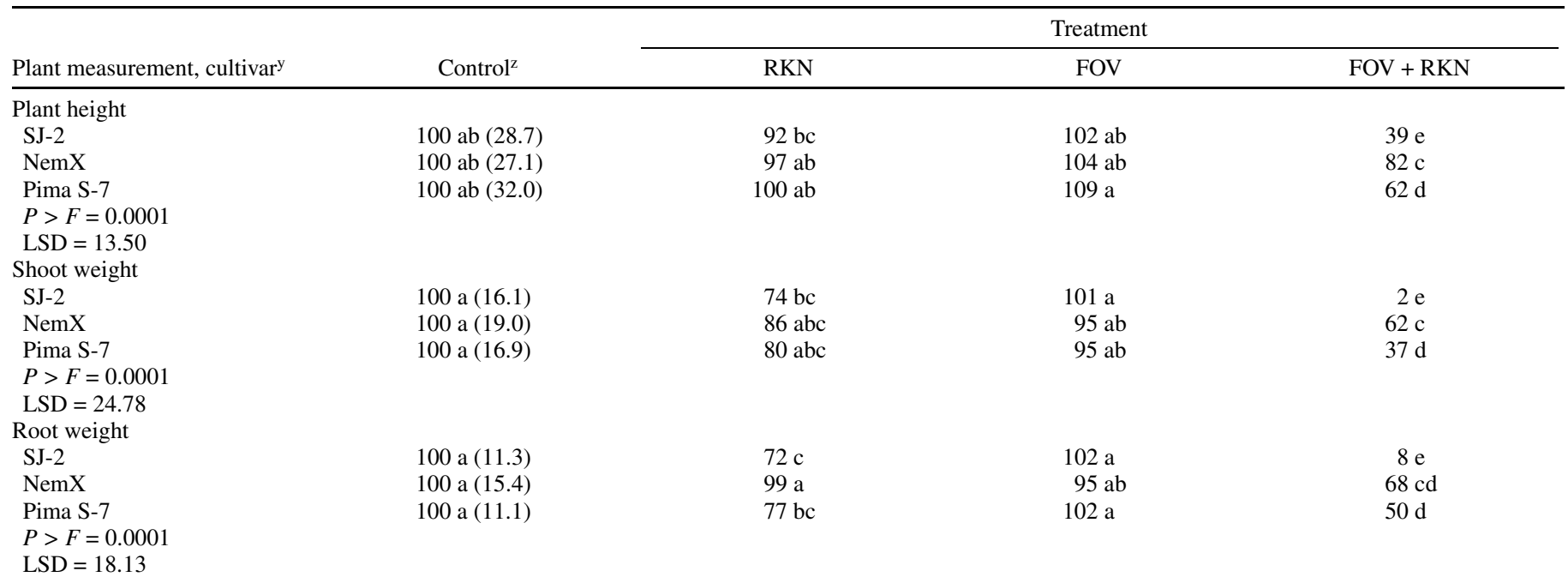

x Observations were made 60 days after inoculation. Ten-day-old seedlings grown in 10-cm-diameter pots filled with sandy soil were inoculated with 20,000 M. incognita eggs, $30 \times 10^{6}$ F. oxysporum f. sp. vasinfectum spores, or both. Data are mean percentages of each plant growth parameter, calculated from the mean value of the control as $100 \%$ for each genotype. Means with the same letter are not different. Data were compared among all treatments and all cultivars for each parameter.

${ }^{y} P=$ probability level of analysis of variance and LSD $=$ least significant difference at the 0.05 level.

$\mathrm{z}$ Values in parentheses are means of control plant height $(\mathrm{cm})$, shoot weight $(\mathrm{g})$, and root weight $(\mathrm{g})$. 


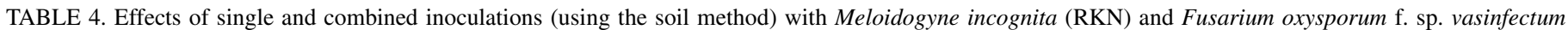
(FOV) race 1 on plant growth of three cotton cultivars (Acala SJ-2, Acala NemX, and Pima S-7) ${ }^{\mathrm{x}}$

\begin{tabular}{|c|c|c|c|c|}
\hline \multirow[b]{2}{*}{ Plant measurement, cultivar ${ }^{y}$} & \multirow[b]{2}{*}{ Control $^{\mathrm{Z}}$} & \multicolumn{3}{|c|}{ Treatment } \\
\hline & & RKN & FOV & $\mathrm{FOV}+\mathrm{RKN}$ \\
\hline \multicolumn{5}{|l|}{ Plant weight } \\
\hline $\mathrm{SJ}-2$ & $100 \mathrm{ab}(32.2)$ & 89 bc & $71 \mathrm{~d}$ & $35 \mathrm{e}$ \\
\hline NemX & $100 \mathrm{ab}(27.7)$ & $101 \mathrm{ab}$ & $104 \mathrm{a}$ & $87 \mathrm{c}$ \\
\hline Pima S-7 & $100 \mathrm{ab}(38.8)$ & $90 \mathrm{bc}$ & 92 abc & $62 \mathrm{~d}$ \\
\hline \multicolumn{5}{|l|}{$P>F=0.0001$} \\
\hline \multicolumn{5}{|l|}{$\mathrm{LSD}=12.57$} \\
\hline \multicolumn{5}{|l|}{ Shoot weight } \\
\hline $\mathrm{SJ}-2$ & 100 a (18.6) & $82 \mathrm{bc}$ & $48 \mathrm{~d}$ & $2 \mathrm{e}$ \\
\hline NemX & 100 a (16.9) & $101 \mathrm{ab}$ & $101 \mathrm{a}$ & $71 \mathrm{c}$ \\
\hline Pima S-7 & 100 a (19.7) & $80 \mathrm{c}$ & $91 \mathrm{abc}$ & $35 \mathrm{~d}$ \\
\hline \multicolumn{5}{|l|}{$P>F=0.0001$} \\
\hline \multicolumn{5}{|l|}{$\mathrm{LSD}=19.45$} \\
\hline \multicolumn{5}{|l|}{ Root weight } \\
\hline $\mathrm{SJ}-2$ & $100 \mathrm{a}(13.3)$ & $84 \mathrm{bc}$ & $61 \mathrm{~d}$ & $4 \mathrm{e}$ \\
\hline NemX & $100 \mathrm{a}(12.2)$ & $106 \mathrm{ab}$ & $109 \mathrm{a}$ & $76 \mathrm{~cd}$ \\
\hline Pima S-7 & 100 a (9.5) & $104 \mathrm{ab}$ & $106 \mathrm{ab}$ & $54 \mathrm{~d}$ \\
\hline \multicolumn{5}{|l|}{$P>F=0.0001$} \\
\hline \multicolumn{5}{|l|}{$\mathrm{LSD}=22.42$} \\
\hline \multicolumn{5}{|c|}{$\begin{array}{l}\text { x Observations were made } 60 \text { days after inoculation. Each } 10-\mathrm{cm} \text {-diameter pot contained sandy soil with or without } 30 \times 10^{6} \text { F. oxysporum f. sp. vasinfectum } \\
\text { spores (mixed into the soil before seeding). In treatments including nematodes, } 20,000 \text { M. incognita eggs were inoculated over the seed before it was covered. } \\
\text { Data are mean percentages of each plant growth parameter, calculated from the mean value of the control as } 100 \% \text { for each genotype. Means with the same letter } \\
\text { are not different. Data were compared among all treatments and all cultivars for each parameter. }\end{array}$} \\
\hline $\mathrm{z}$ Values in parentheses are me & rol plant height & & & \\
\hline
\end{tabular}

TABLE 5. Effects of single and combined inoculations with Meloidogyne incognita $(\mathrm{RKN})$ and Fusarium oxysporum $\mathrm{f}$. sp. vasinfectum (FOV) race 1 on nematode egg production on three cotton cultivars (Acala SJ-2, Acala NemX, and Pima S-7) using the seedling and the soil inoculation methods ${ }^{\mathrm{y}}$

\begin{tabular}{lccccc}
\hline & \multicolumn{3}{c}{ Treatment and inoculation method } \\
\cline { 2 - 3 } \cline { 5 - 6 } Cultivar & \multicolumn{2}{c}{ Seedling method } & & \multicolumn{2}{c}{ Soil method } \\
\cline { 2 - 3 } \cline { 5 - 6 } SJ-2 & RKN & RKN + FOV & & RKN & RKN + FOV \\
NemX & $2.040 \mathrm{c}$ & $1.514 \mathrm{c}$ & & $1.315 \mathrm{c}$ & $1.375 \mathrm{c}$ \\
Pima S-7 & $4.500 \mathrm{a}$ & $4.416 \mathrm{a}$ & & $3.918 \mathrm{a}$ & $3.467 \mathrm{a}$ \\
$P>F$ & \multicolumn{2}{c}{0.0001} & & \multicolumn{2}{c}{0.0001} \\
LSD & \multicolumn{2}{c}{0.727} & & \multicolumn{2}{c}{0.883} \\
\hline
\end{tabular}

y Observations were made 60 days after inoculation. Nematode egg data were transformed to $\log _{10}($ eggs per gram root +1$)$ for analysis and the values are means for nine replicate plants per treatment. $P=$ probability level of analysis of variance and LSD = least significant difference at the 0.05 level within an inoculation method. Means within an inoculation method with the same letter are not different.

${ }^{\mathrm{z}}$ Data were compared among treatments of RKN alone and RKN + FOV in all three cultivars.

(C. Wang, unpublished data), and to Verticillium wilt in an $\mathrm{F}_{2}$ (resistant Pima S-7 $\times$ susceptible Acala 44) population (5).

This study identified two AFLP markers that are linked to Fov1 in Pima S-7. For effective marker-assisted selection, markers must be tightly linked to the resistance genes. In our study, we had only $50 \mathrm{~F}_{2}(\mathrm{Pima} \mathrm{S}-7 \times \mathrm{NemX})$ plants to map Fov1, and the two AFLP markers were not tightly linked to Fov1. Therefore, these markers would not be useful for indirect selection of Fov1-based wilt resistance, and converting them to PCR-based markers may not be worthwhile. However, the two AFLP markers could be useful for fine-mapping studies and map-based cloning of the Fov 1 gene. To map Fovl at the chromosome level, we will use microsatellite markers with known chromosome positions to screen the $F_{2}$ population. In the meantime, we will use more $\mathrm{F}_{2}$ plants based on phenotype screening of $\mathrm{F}_{2: 3}$ families for fine localization.

The root-cut dip method of inoculation is useful for screening wilt resistance in cotton and has been used widely for pathogenicity tests of $F$. oxysporum f. sp. vasinfectum in cotton $(20,30,31)$. Other inoculation methods, such as the seedling and soil methods

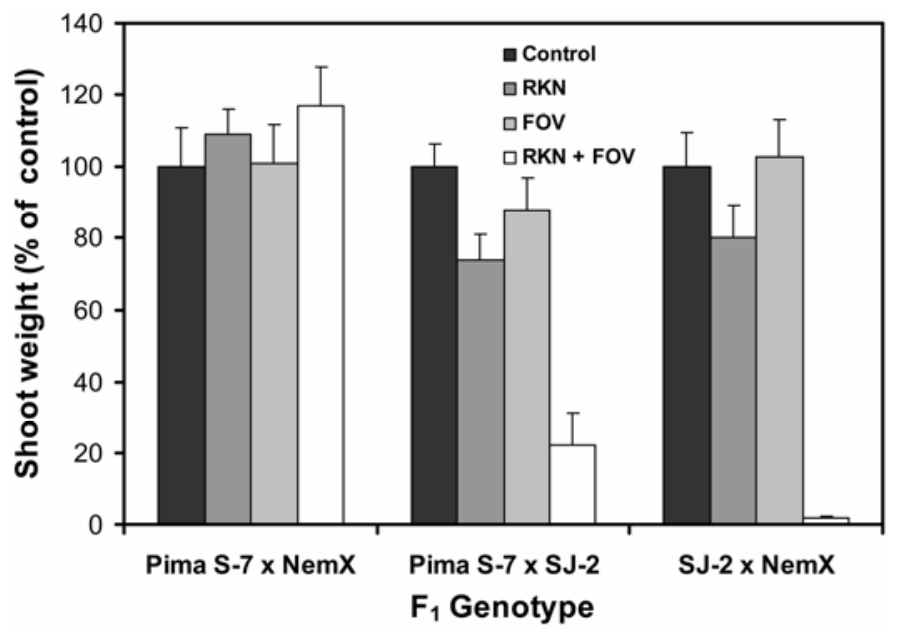

Fig. 3. Effects of single and combined inoculations with Meloidogyne incognita (RKN) and Fusarium oxysporum f. sp. vasinfectum (FOV) race 1 (added to soil at planting) on shoot weight of three $F_{1}$ cotton genotypes. Observations were made 60 days after inoculation. Data are mean percentages of each plant shoot weight, calculated from the mean value of the control as $100 \%$ for each genotype. Bars show \pm one standard error.

used in this study and the stem puncture method $(7,16,28)$, also are informative but give less discriminating wilt disease reactions. When $F$. oxysporum f. sp. vasinfectum was added alone by either the seedling or soil method, we observed no differences in the aboveground symptoms exhibited by the three cultivars (Acala SJ-2, Acala NemX, and Pima S-7); these symptoms were always mild. In contrast, when the fungus was added with the nematode, we observed clear differences in symptom expression among the cultivars regardless of the fungus inoculation method.

Previous studies have shown important effects of pathogen resistance in cotton on the nematode-wilt disease complex, including the breakdown of wilt resistance by nematode infection $(6,17$, 32 ). Those studies, however, were based on genetically undefined resistance traits. Here, we were able to assess the pathogen and host interactions in the disease complex with cotton genotypes carrying characterized resistance genes, Fovl-mediated wilt resis- 
tance, and rknl-mediated nematode resistance (34). The greatest reduction in plant growth occurred in Acala SJ-2, followed by Pima S-7 and Acala NemX. These genotype differences can be explained by their respective nematode and wilt resistance profiles. Acala SJ-2 is susceptible to both $M$. incognita and $F$. oxysporum $\mathrm{f}$. sp. vasinfectum race 1 , as shown in the current experiments. Pima S-7, possessing gene Fov1, is resistant to F oxysporum f. sp. vasinfectum race 1 , but is highly susceptible to $M$. incognita. In these experiments, co-infection of Pima S-7 with $F$. oxysporum f. sp. vasinfectum race 1 and $M$. incognita caused severe wilt disease symptoms, indicating that nematode infection broke the wilt resistance conferred by Fov1. The smaller plant growth reductions and less severe wilt symptoms in Acala NemX in the combined $M$. incognita plus $F$. oxysporum f. sp. vasinfectum race 1 treatment were due to $r k n 1$, a major gene that confers a high level of resistance to $M$. incognita (34). Furthermore, even though Acala NemX is wilt susceptible, it showed lower wilt disease than the highly susceptible Acala SJ-2 on several assay dates and a lower disease profile overall than Acala SJ-2 during the disease progression study.

The root-knot nematode-Fusarium wilt disease complex experiment among three $\mathrm{F}_{1}(\mathrm{NemX} \times \mathrm{SJ}-2$, Pima S-7 $\times \mathrm{NemX}$, and Pima S-7 $\times$ SJ-2) genotypes provided further support for these findings. The $\mathrm{F}_{1}(\mathrm{NemX} \times \mathrm{SJ}-2)$ and $\mathrm{F}_{1}(\mathrm{Pima} \mathrm{S}-7 \times \mathrm{SJ}-2)$ genotypes were nematode susceptible and grew poorly in the presence of both pathogens. However, the root-knot nematode-resistant and wilt-intermediate-resistant $\mathrm{F}_{1}(\mathrm{Pima} \mathrm{S}-7 \times \mathrm{NemX})$ genotype grew better than nematode-resistant and wilt-susceptible parent Acala NemX. Our results indicated that cultivars with resistance to $M$. incognita suffer much less wilt than cultivars with resistance to $F$. oxysporum f. sp. vasinfectum race 1 alone. Nematode resistance combined with intermediate wilt resistance was more effective than nematode resistance alone in protecting plants from the wilt disease. Similar interaction affects have been reported for nematode-wilt disease complex in other crop systems $(4,8,25)$.

The Fusarium sp. caused much more damage to Acala SJ-2 when the fungal inoculum was added to the soil before planting than to the growing seedling. This result indicated that the early seedling stage of Acala SJ-2 (susceptible to both pathogens) is more sensitive to wilt infection than later seedling stages. More severe wilt infection developed in the 7-day-old seedlings than in the 10-day-old seedlings with the root-cut dip method for $F$. oxysporum f. sp. vasinfectum pathogenicity tests (data not shown). Pima S-7 exhibited less severe symptoms when 14-day-old seedlings were inoculated (20) than when 7-day-old seedlings were inoculated in the current study. Thus, how and when plants are inoculated with the pathogens can greatly affect disease expression, and laboratory and greenhouse screens may not represent the true resistance occurring in the field (33).

In the genetic study, severe damage to the roots in Pima S-7 after cutting resulted in five individual plants failing to recover after transplanting. Hillocks (13) also reported that the root-cut dip method may damage the roots and occasionally result in severe wilt even in resistant plants. In addition, we also observed that some plants we expected to be susceptible showed resistance, probably resulting from escaped infection due to large screening tests.

In summary, Pima S-7 was resistant to F. oxysporum f. sp. vasinfectum race 1 , and the resistance was attributed to one gene (Fov1), with allele dosage effects based on genetic and AFLP marker analysis. Nematode resistance and wilt resistance of the host genotype affected the severity of wilt disease in the presence of both $M$. incognita and $F$. oxysporum f. sp. vasinfectum race 1 . In co-inoculations with both pathogens, resistance to root-knot nematodes greatly decreased the wilt symptoms compared with resistance to Fusarium wilt alone.

\section{ACKNOWLEDGMENTS}

This study was funded in part by a Cooperative Research Agreement from Cotton Incorporated and a grant from the University of California Discovery Grant (BioSTAR) Program. We thank S. Oakley of California Planting Cotton Seed Distributors for providing cotton seed; M. Roose and M. Stanghellini for helpful advice; and W. Matthews, T. Mullens, and K. Carter for technical help.

\section{LITERATURE CITED}

1. Abawi, G. S., and Chen, J. 1998. Concomitant pathogen and pest interactions. Pages 135-138 in: Plant and Nematode Interactions. Am. Soc. Argon., Crop Sci. Soc. Am., Soil Sci. Soc. Am., Madison, WI.

2. Anonymous. 1996. Cotton disease loss estimate committee report. Page 227 in: Proc. Beltwide Cotton Prod. Res. Conf. Natl. Cotton Council Am., Memphis, TN.

3. Baker, K. F. 1957. The U.C. system for producing healthy containergrown plants. Calif. Agric. Exp. Stn. Man. 23:1-332.

4. Bertrand, B., Nunez, C., and Sarah, J. L. 2000. Disease complex in coffee involving Meloidogyne arabicida and Fusarium oxysporum. Plant Pathol. 49:383-388.

5. Bolek, Y., Bell, A. A., El-Zik, K. M., Thaxton, P. M., and Magill, C. W. 2005. Reaction of cotton cultivars and an $F_{2}$ population to stem inoculation with isolates Verticillium dahliae. J. Phytopathol. 153:269273.

6. Brown, A. G. P. 1964. Field trials with three Fusarium wilt resistant cotton selections in Tanganyika. Empire Cotton Growing Rev. 41:112114.

7. Bugbee, W. M., and Sappenfield, W. P. 1972. Greenhouse evaluation of Verticillium, Fusarium and root-knot nematode on cotton. Crop Sci. 12:112-114.

8. Castillo, P., Navas-Cortes, J. A., Gomar-Tinoco, D., Vito, M. D., and Jimenez-Diaz, R. M. 2003. Interactions between Meloidogyne artiellia, the cereal legume root-knot nematode, and Fusarium oxysporum f. sp. ciceris race 5 in chickpea. Phytopathology 93:1513-1523.

9. Davis, R. D., Moore, N. Y., and Kochman, J. K. 1996. Characterization of a population of Fusarium oxysporum f. sp. vasinfectum causing wilt of cotton in Australia. Aust. J. Agric. Res. 47:1143-1156.

10. DeVay, J. E., Gutierrez, A. P., Pullman, G. S., Wakeman, R. J., Garber, R. H., Jeffers, D. P., Smith, S. N., Goodell, P. B., and Roberts, P. A. 1997. Inoculum densities of Fusarium oxysporum f. sp. vasinfectum and Meloidogyne incognita in relation to the development of Fusarium wilt and phenology of cotton plants (Gossypium hirsutum). Phytopathology 87:341-346.

11. Garber, R. H., Jorgenson, E. C., Smith, S., and Hyer, A. H. 1979. Interaction of population levels of Fusarium oxysporum f. sp. vasinfectum and Meloidogyne incognita on cotton. J. Nematol. 11:133-137.

12. Goodell, P. B., Estil, K. E., and Assemi, M. 1992. Preliminary results of two years survey of cotton root-knot nematode in the San Joaquin Valley. Page 188 in: Proc. Beltwide Cotton Prod. Res. Conf. Natl. Cotton Council Am., Memphis, TN.

13. Hillocks, R. L. 1984. Production of cotton varieties with resistance to Fusarium with special reference to Tanzania. Trop. Pest Manage. 30: 234-246.

14. Hussey, R. S., and Barker, K. R. 1973. A comparison of methods of collecting inocula of Meloidogyne spp. including a new technique. Plant Dis. Rep. 57:1025-1028.

15. Hyer, A. H., Jorgenson, E. C., Garber, R. H., and Smith, S. 1979. Resistance to root-knot nematode in control of root-knot nematode-Fusarium wilt disease complex in cotton. Crop Sci. 19:898-901.

16. Ibrahim, G., and Nirenberg, H. I. 1993. Response of some Sudanese cotton cultivars to race 1 and 5 of Fusarium oxysporum f. sp. vasinfectum. J. Plant Dis. Prot. 100:645-651.

17. Jeffers, D. P., and Roberts, P. A. 1993. Effect of planting date and host genotype on the root-knot nematode-Fusarium wilt disease complex of cotton. Phytopathology 83:645-654.

18. Jones, J. E., and Birchfield, W. 1967. Resistance of the experimental cotton variety, Bayou, and related strains to root knot nematode and Fusarium wilt. Phytopathology 57:1327-1331.

19. Jorgenson, E. C. 1979. Granular nematicides as adjuncts to fumigants for control of root-knot nematodes. J. Nematol. 11:144-150.

20. Kim, Y., Hutmacher, R. B., and Davis, R. M. 2005. Characterization of California isolates of Fusarium oxysporum f. sp. vasinfectum. Plant Dis. 89:366-372.

21. Kosambi, D. D. 1944. The estimation of map distances from recombination values. Ann. Eugen. 12:172-175.

22. Michelmore, R. W., Paran, I., and Kesseli, R. V. 1991. Identification of markers linked to disease resistance genes by bulked segregant 
analysis: A rapid method to detect markers in specific genomic regions by using segregating populations. Proc. Natl. Acad. Sci. USA 88:98289832.

23. Netzer, D., Tal, Y., Marani, A., and Weintall, C. 1985. Resistance of interspecific cotton hybrids (Gossypium hirsutum $\times$ G. barbadense containing G. harknessii cytoplasm) to Fusarium wilt. Plant Dis. 69:312-313.

24. Ogallo, J. L., Goodell, P. B., Eckert, J., and Roberts, P. A. 1997. Evaluation of NemX, a new cultivar of cotton with high resistance to Meloidogyne incognita. J. Nematol. 29:531-537.

25. Roberts, P. A., Frate, C. A., Matthews, W. C., and Osterli, P. P. 1995. Interactions of virulent Meloidogyne incognita and Fusarium wilt on resistant cowpea genotypes. Phytopathology 85:1288-1294.

26. Roberts, P. A., Matthews, W. C., and Ehlers, J. D. 1996. New resistance to virulent root-knot nematodes linked to the $R k$ locus of cowpea. Crop Sci. 36:889-894.

27. Shepherd, R. L. 1986. Cotton resistance to the root-knot-Fusarium wilt complex. II. Relation to root-knot resistance and its implications on breeding for resistance. Crop Sci. 26:233-237.

28. Shepherd, R. L., and Kappelman, A. J. 1986. Cotton resistance to root knot-Fusarium wilt complex. I. Relation to Fusarium wilt resistance and its implications on breeding for resistance. Crop Sci. 26:228-232.

29. Smith, A. L., and Dick, J. B. 1960. Inheritance of resistance to Fusarium wilt in Upland and Sea Island cottons as complicated by nematodes under field conditions. Phytopathology 50:44-48.

30. Smith, S. N., DeVay, J. E., Hsieh, W. H., and Lee, H. J. 2001. Soil-borne populations of Fusarium oxysporum f. sp. vasinfectum, a cotton wilt fungus in California fields. Mycologia 93:737-747.

31. Smith, S. N., Jeffers, D. P., and DeVay, J. E. 1994. Effects of glucose and biotin on the growth and sporulation of Fusarium species, especially pathogenic and nonpathogenic isolates of Fusarium oxysporum. Mycologia 86:547-554.

32. Starr, J. L., and Martyn, R. D. 1991. Reaction of cotton cultivars to Fusarium wilt and root-knot nematodes. Nematropica 21:51-58.

33. Starr, J. L., and Veech, J. A. 1986. Susceptibility to root-knot nematodes in cotton lines resistant to the Fusarium wilt/root-knot complex. Crop Sci. 26:543-546.

34. Wang, C., Ulloa, M., and Roberts, P. A. 2006. Identification and mapping of microsatellite markers linked to a root-knot nematode resistance gene (rkn1) in Acala NemX cotton (Gossypium hirsutum L.). Theor. Appl. Genet. 112:770-777. 